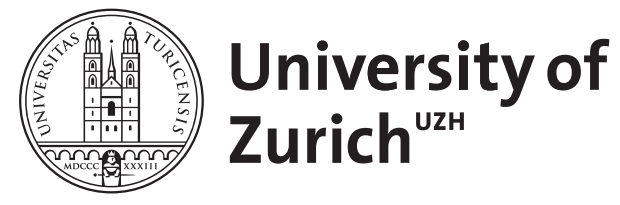

\title{
Antimetastatic properties of low molecular weight heparin
}

Laubli, H ; Varki, A ; Borsig, L

DOI: https://doi.org/10.1200/JCO.2016.66.4607

Posted at the Zurich Open Repository and Archive, University of Zurich

ZORA URL: https://doi.org/10.5167/uzh-130819

Journal Article

Published Version

Originally published at:

Laubli, H; Varki, A; Borsig, L (2016). Antimetastatic properties of low molecular weight heparin. Journal of Clinical Oncology, 34(21):2560-2561.

DOI: https://doi.org/10.1200/JCO.2016.66.4607 


\section{Antimetastatic Properties of Low Molecular Weight Heparin}

To the EdIToR: The well-performed and important FRAGMATIC (Dalteparin in Preventing Blood Clots in Patients With Lung Cancer) trial reported by Macbeth et $\mathrm{al}^{1}$ concluded that the addition of prophylactic doses of the low molecular weight heparin (LMWH) dalteparin for 24 weeks to standard of care in patients with lung cancer did not improve overall survival; the rate of venous thromboembolism was significantly reduced but at the cost of an increase in bleeding complications. There was also no significant effect on metastasis in the group that received dalteparin. Although the results are important for this particular clinical situation, we are concerned that generalization of the concept that LMWHs do not have antitumor or antimetastatic effects could hamper further development of effective treatment algorithms, including LMWHs, for patients with cancer.

Heparins are highly sulfated glycosaminoglycans, and we previously reported the impact of heparins (in particular, tinzaparin) in preclinical models ${ }^{2,3}$ that demonstrated strong inhibition of tumor colonization via interference with binding of P- and L-selectin to cancer mucins. ${ }^{2,4}$ Of note, dalteparin is not a good inhibitor of selectin-mediated interactions compared with tinzaparin and unfractionated heparin. ${ }^{5}$ Tinzaparin or unfractionated heparin have higher negative charge and longer chains of glycosaminoglycans and thus they may be favored over dalteparin as antimetastatic agents. ${ }^{5}$ Heparin inhibition of P-selectin-mediated interactions reduced platelet binding to mucins on tumor cells, increased immunemediated clearing during hematogenous dissemination, ${ }^{2}$ and blocked L-selectin-mediated recruitment of monocytes required for tumor cell extravasation and organ colonization., ${ }^{4,6}$

Although the authors should be congratulated for having chosen overall survival (and not only the occurrence of venous thromboembolism) as an end point, the FRAGMATIC trial was not designed to examine the antimetastatic properties of LMWHs. ${ }^{1}$ Studies that test LMWHs with better antimetastatic properties such as tinzaparin should be conducted in a setting clearly defined for preventing metastasis. The best environment for testing an antimetastatic agent would be localized cancers that are being definitively treated by surgery or radiation together with chemotherapy. Trials that test tinzaparin in the adjuvant or perioperative setting for patients with lung cancer (eg, NCT00475098; Effect of Low Molecular Weight Heparin: Tinzaparin in Lung Tumours [TILT]) and resectable cancer of the colon (eg, NCT01455831; Extended Peri-operative Tinzaparin to Improve Disease-Free Survival in Patients With Resectable Colorectal Cancer [PERIOP-01]) are ongoing. They are better suited for answering questions about the antimetastatic properties of LMWHs.

\section{Heinz Läubli}

University Hospital Basel, Basel, Switzerland

\section{Ajit Varki}

University of California, San Diego, CA

\section{Lubor Borsig}

University of Zürich, Zürich, Switzerland

\section{AUTHORS' DISCLOSURES OF POTENTIAL CONFLICTS OF INTEREST}

Disclosures provided by the authors are available with this article at www.jco.org.

\section{REFERENCES}

1. Macbeth F, Noble S, Evans J, et al: Randomized phase III trial of standard therapy plus low molecular weight heparin in patients with lung cancer: FRAGMATIC trial. J Clin Oncol 34:488-494, 2016

2. Borsig $L$, Wong $R$, Feramisco J, et al: Heparin and cancer revisited Mechanistic connections involving platelets, P-selectin, carcinoma mucins, and tumor metastasis. Proc Natl Acad Sci USA 98:3352-3357, 2001

3. Wahrenbrock $M$, Borsig $L$, Le $D$, et al: Selectin-mucin interactions as a probable molecular explanation for the association of Trousseau syndrome with mucinous adenocarcinomas. J Clin Invest 112:853-862, 2003

4. Läubli $H$, Stevenson JL, Varki $A$, et al: L-selectin facilitation of metastasis involves temporal induction of Fut7-dependent ligands at sites of tumor cell arrest. Cancer Res 66:1536-1542, 2006

5. Stevenson JL, Choi SH, Varki A: Differential metastasis inhibition by clinically relevant levels of heparins: Correlation with selectin inhibition, not antithrombotic activity. Clin Cancer Res 11:7003-7011, 2005

6. Läubli H, Spanaus KS, Borsig L: Selectin-mediated activation of endothelia cells induces expression of CCL5 and promotes metastasis through recruitment of monocytes. Blood 114:4583-4591, 2009

DOI: 10.1200/JCO.2016.66.4607; published online ahead of print at www.jco.org on May 16, 2016. 


\section{AUTHORS' DISCLOSURES OF POTENTIAL CONFLICTS OF INTEREST}

Antimetastatic Properties of Low Molecular Weight Heparin

The following represents disclosure information provided by authors of this manuscript. All relationships are considered compensated. Relationships are self-held unless noted. I = Immediate Family Member, Inst = My Institution. Relationships may not relate to the subject matter of this manuscript. For more information about ASCO's conflict of interest policy, please refer to www.asco.org/rwc or jco.ascopubs.org/site/ifc.

\section{Heinz Läubli}

Consulting or Advisory Role: Merck Sharp \& Dohme (Inst), Bristol-Myers Squibb (Inst)
Ajit Varki

No relationship to disclose

Lubor Borsig

No relationship to disclose 